\title{
Supramolecular alloying as a facile approach to control crystallinity and morphology in polymer nanostructures
}

Eric P. Bruckner, Tine Curk, Luka Đorđević, Ziwei Wang, Ruomeng Qiu, Adam Dannenhoffer, Hiroaki Sai, Erik Luijten, Samuel I. Stupp

Materials Science and Engineering, Northwestern University

ACS Spring 2020 National Meeting

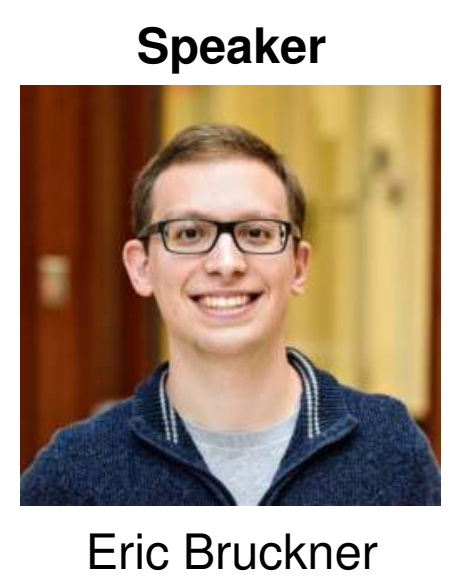




\section{Length Scales of Self-Assembly}

\section{Molecular \\ Structure}

Nano-

Structure
Micro-

Structure
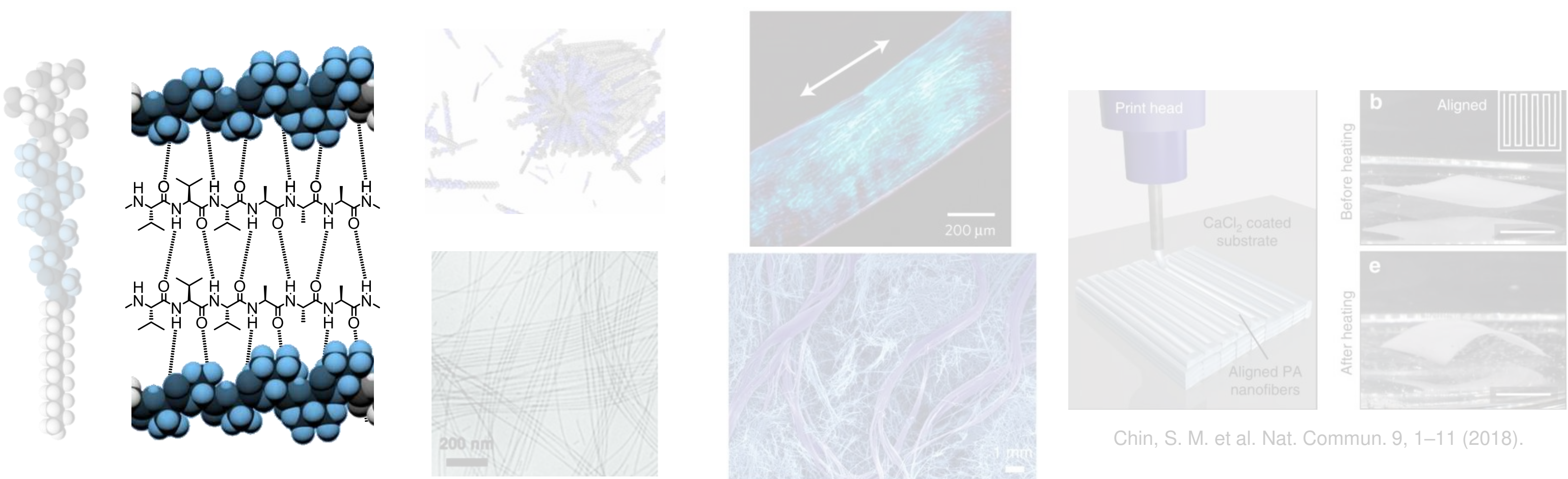

Chin, S. M. et al. Nat. Commun. 9, 1-11 (2018).

Zhang, S. et al. Nat. Mater. 9, 594-601 (2010).

Freeman, R. et al. Science 362, 808-813 (2018). $1 \AA$ 1 11711 $1 \mathrm{~nm}$ $10 \mathrm{~nm}$ $100 \mathrm{~nm}$ $1 \mu \mathrm{m}$ $10 \mu \mathrm{m}$ $100 \mu \mathrm{m}$ $1 \mathrm{~mm}$

गाTा Northwestern |

While the field has developed many strategies to control the nano-, micro-, and macro-structures, a remaining challenge in the field is controlling the arrangement of macromolecules at sub-nanometer length scales. Specifically, this requires methods to control the crystal structure of molecules in supramolecular polymers. 


\section{Supramolecular Polymers}
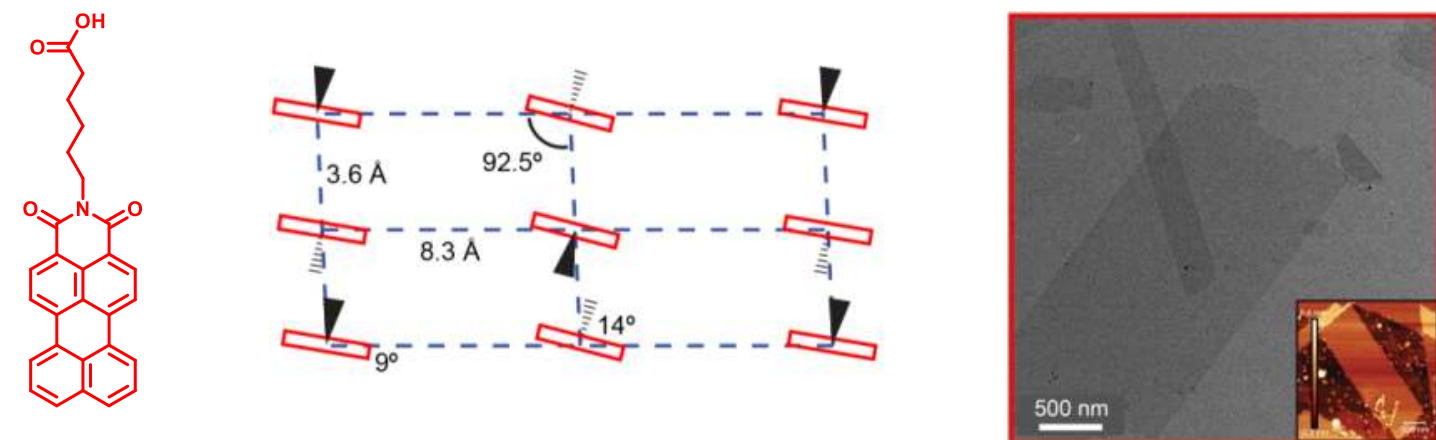

Weingarten, A. S. et al. Nat. Chem. 6, 964-970 (2014)

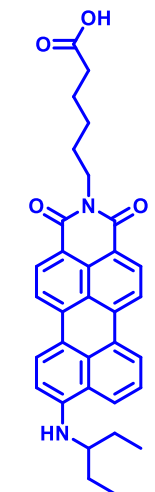

$$
\text { 倠) }
$$

Kazantsev, R. V. et al. Chem 4, 1596-1608 (2018)

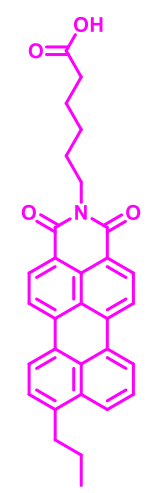

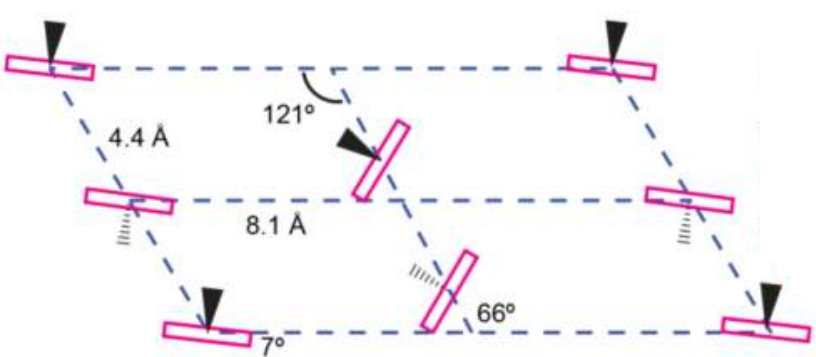

Stupp Group: J. Am. Chem. Soc. 139, 6120-6127 (2017)

\section{Covalent Polymers}
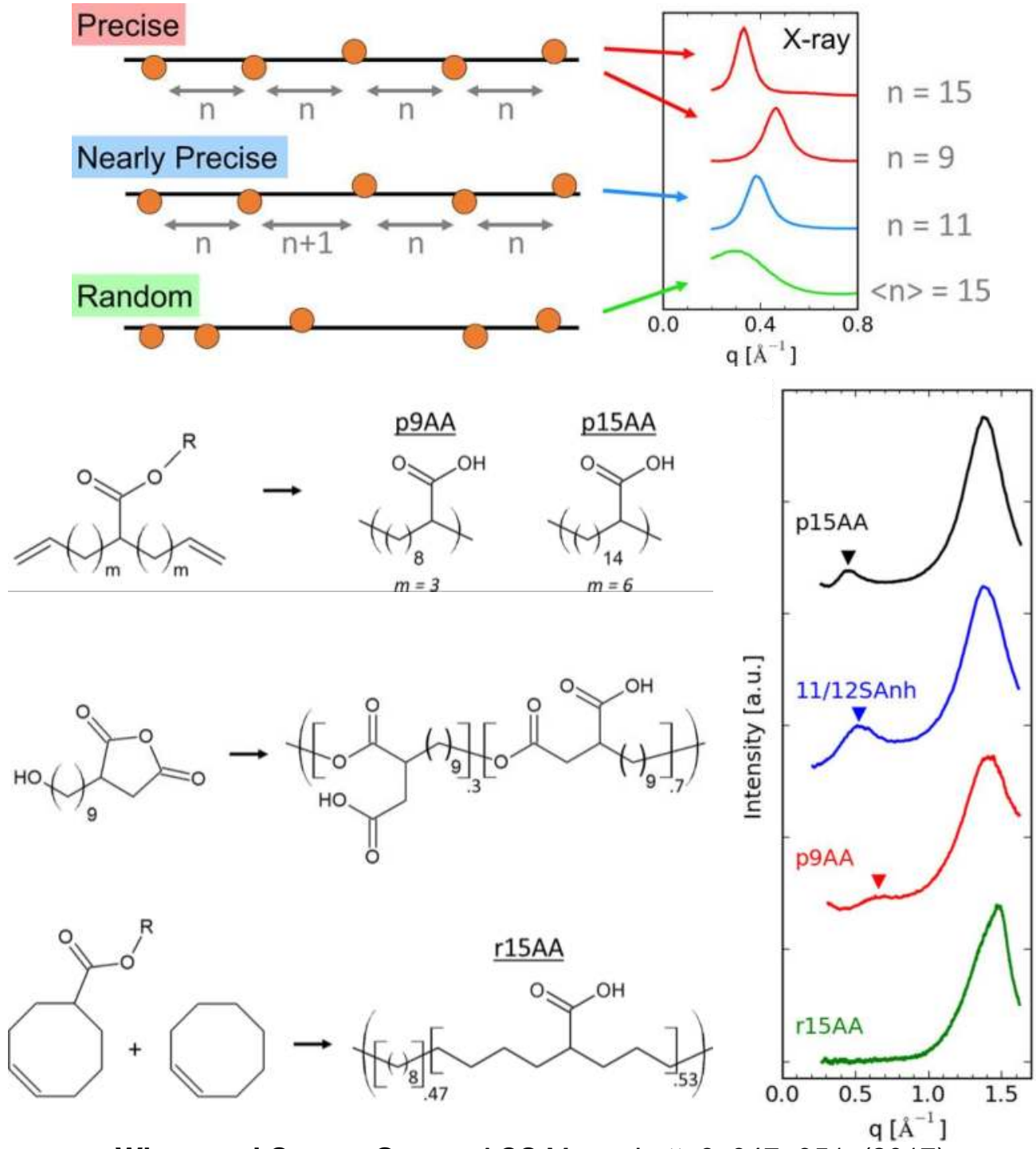

Winey and Coates Group: ACS Macro Lett. 6, 947-951, (2017)

\section{Northwestern ENGINEERING}

Recently, promising work has been done to control the crystal structures in supramolecular and covalent polymer systems. For supramolecular polymers, the Stupp group has looked at a class of chromophores that self-assemble in 2D crystals where the crystal structure can be tuned by changing the dipole moment or steric bulk of the chromophores through synthetic modifications. In covalent polymers, the Winey and Coates group showed that crystallinity and lattice spacing of lamellar phases in ionomers could be tuned through sequence defined polymers. 


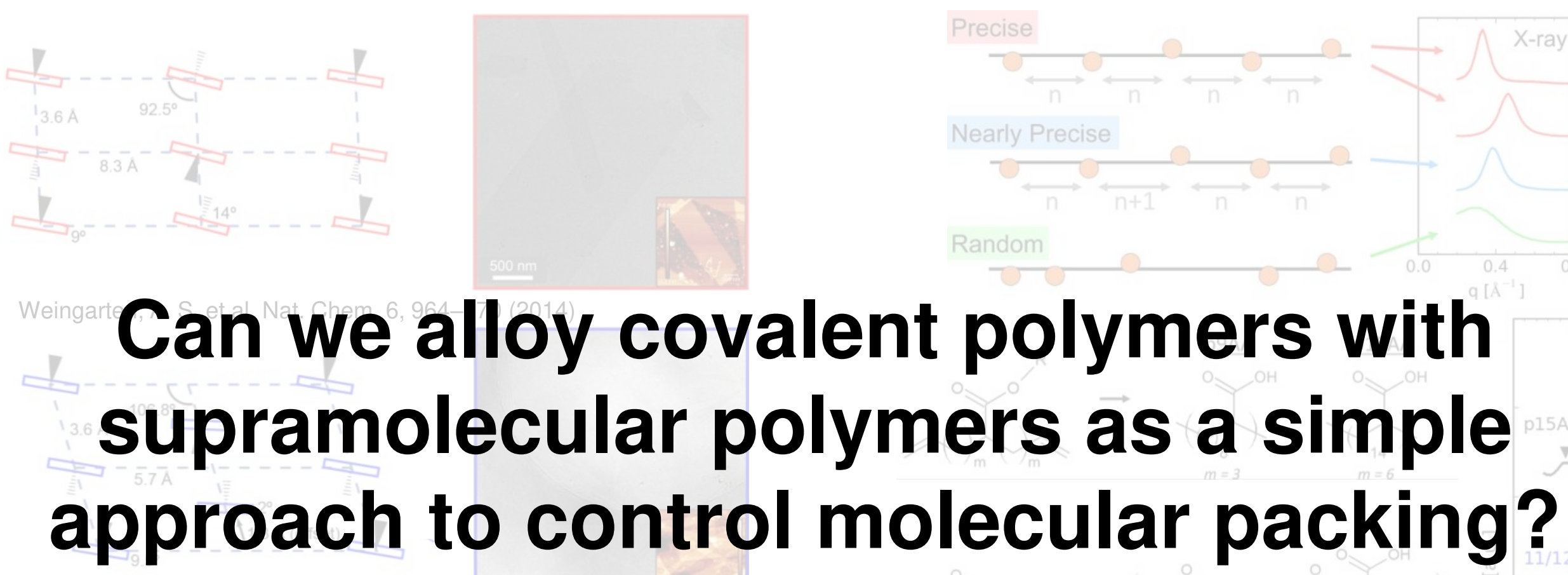

While the use of synthetic modifications is a powerful tool for changing the crystallinity and molecular packing in self-assembled materials, I was interested in developing more facile approaches for controlling crystallinity in supramolecular polymers. In the rest of the presentation, I will borrow concepts from traditional materials science and show how we can control crystal structure and nanostructure morphology of polymeric materials by forming an alloy between covalent polymers and supramolecular polymers. 


\section{Chromophore Amphiphile}

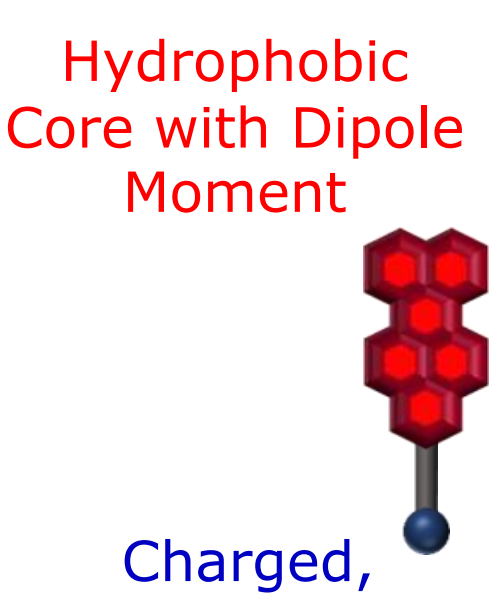

Hydrophilic Tail
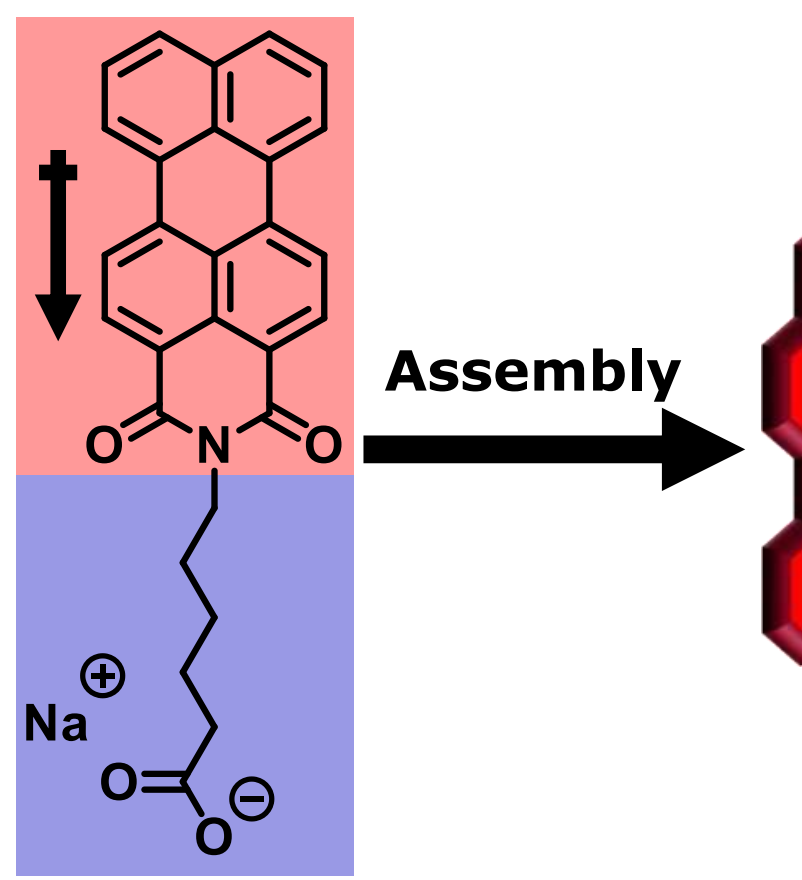

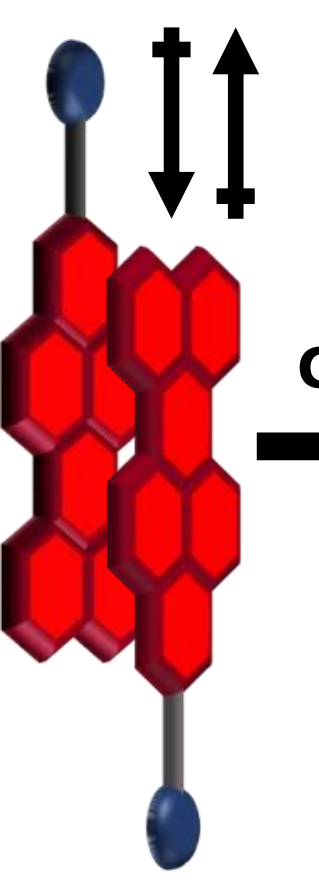

\section{Crystallization}

Salt $=0$

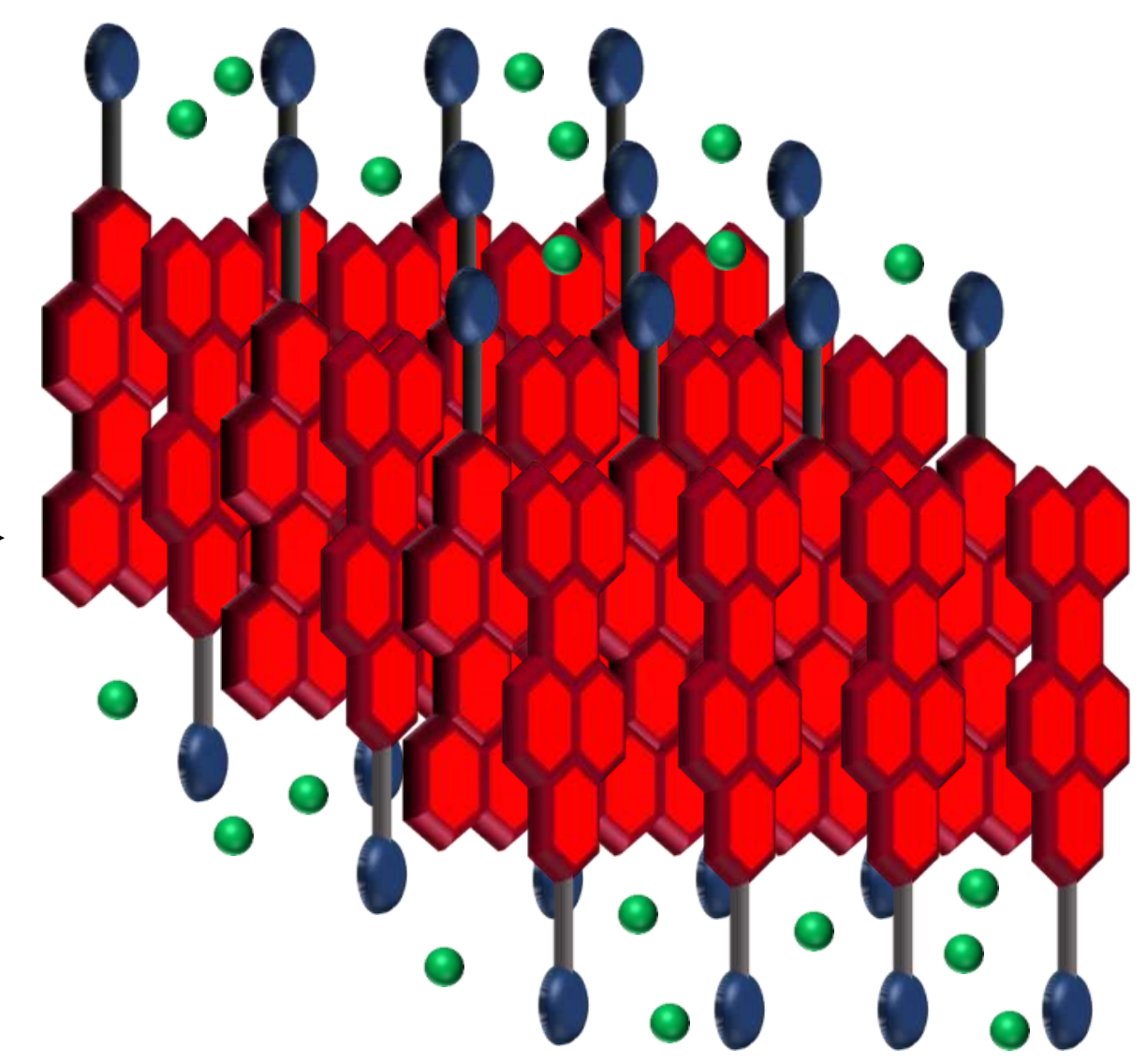

To test this approach, I started with a known supramolecular monomer developed by our group that could assemble into crystalline materials. I chose to use a chromophore amphiphile (CA) based on perylene monimides (PMI) that consists of a hydrophobic core with a strong dipole moment and a charged, hydrophilic tail. These monomers selfassemble in an anti-parallel fashion due to dipolar interactions and can crystallize into $2 \mathrm{D}$ nanostructures in a dielectrically screened, aqueous environment. 

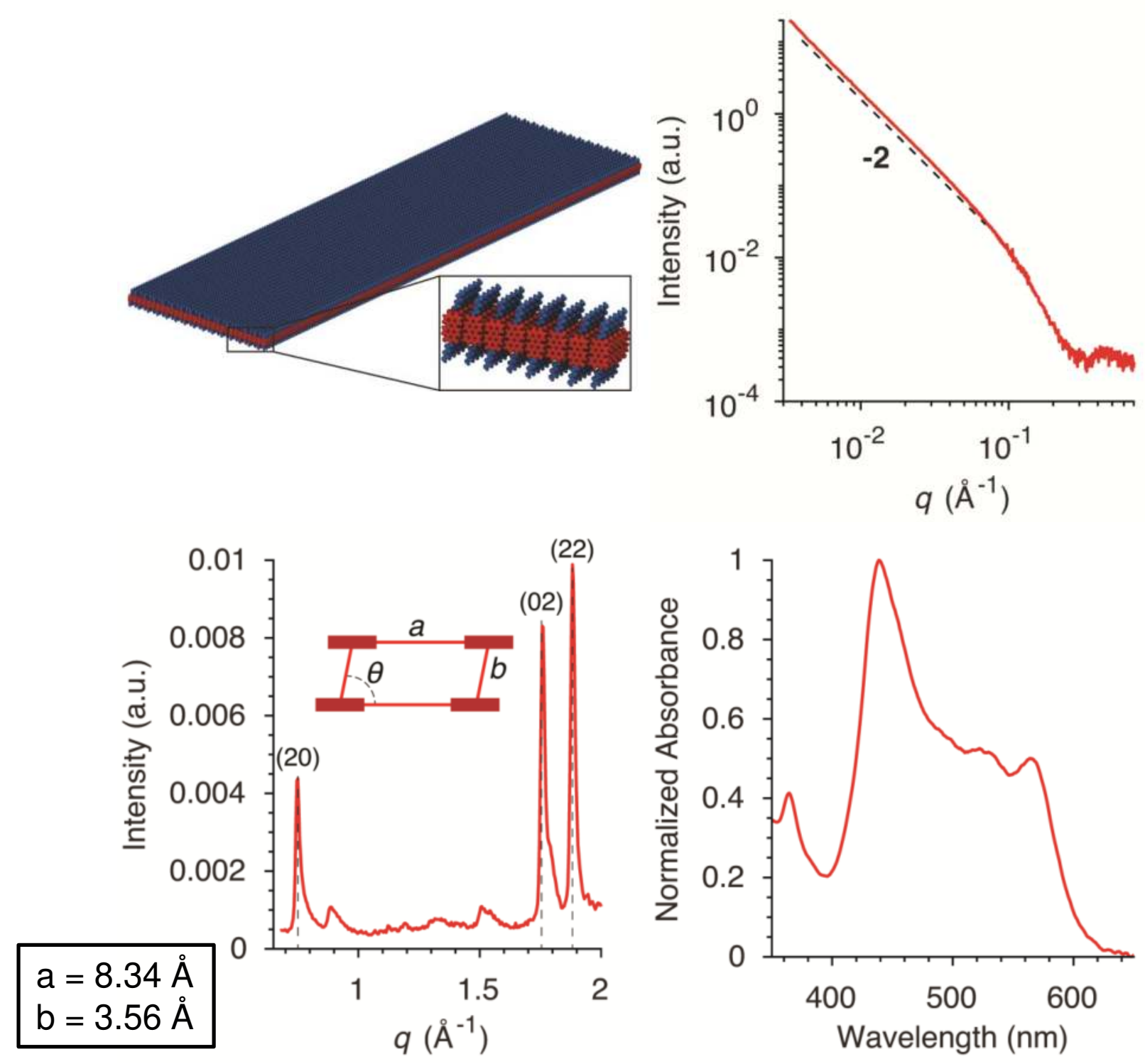

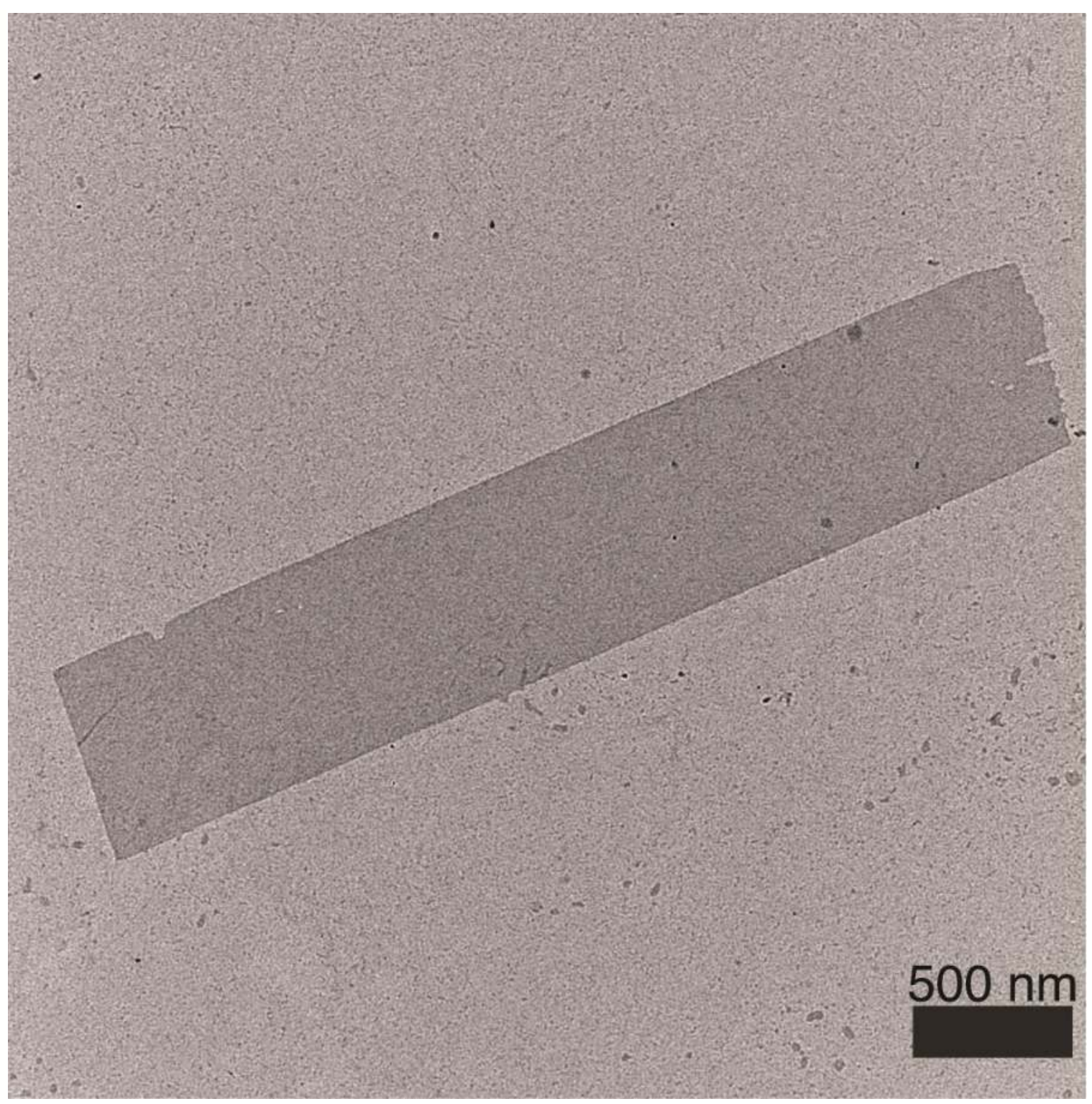

Northwestern | ENcoancescanouefing

Experimentally, the nanostructures of these materials can be supported by small angle X-ray scattering (SAXS) and transmission electron microscopy (TEM). The crystal structure can be determined as a 2D oblique lattice ( $\beta$-phase) by wide angle X-ray scattering (WAXS). 


\section{Covalent Polymer Synthesis}
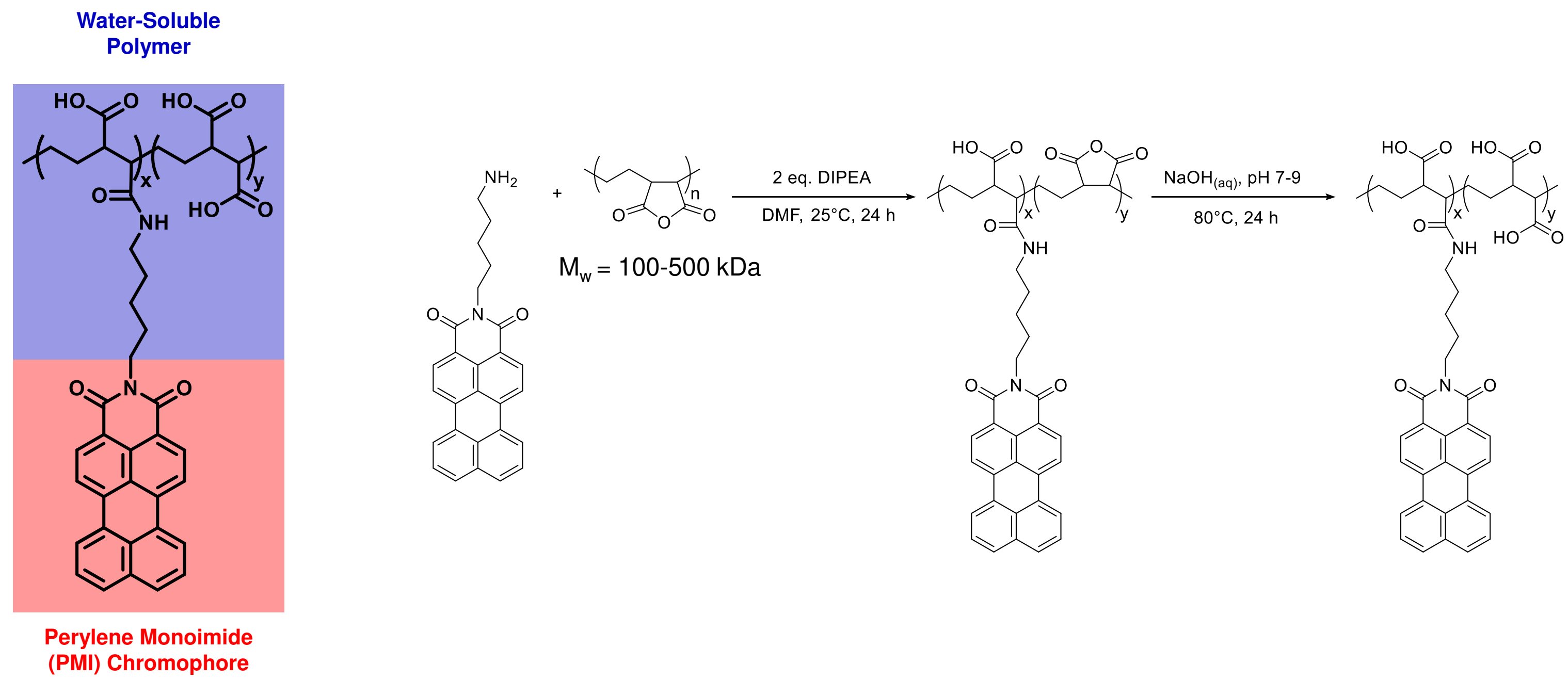

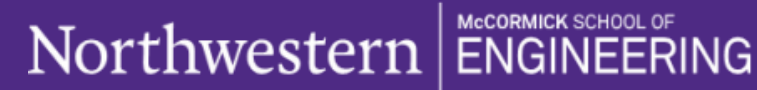

Next, we designed a covalent polymer with a similar structure to the PMI chromophore amphiphile. The structure we chose incorporated a hydrophilic, water soluble polymer functionalized with pendant PMI moieties intended to strongly associate with PMI chromophore amphiphile. The polymer was synthesized by partially functionalizing poly(ethylenealt-maleic anhydride) with an amine terminated PMI-based chromophore and hydrolyzing the remaining anhydride moieties to yield a random copolymer. 

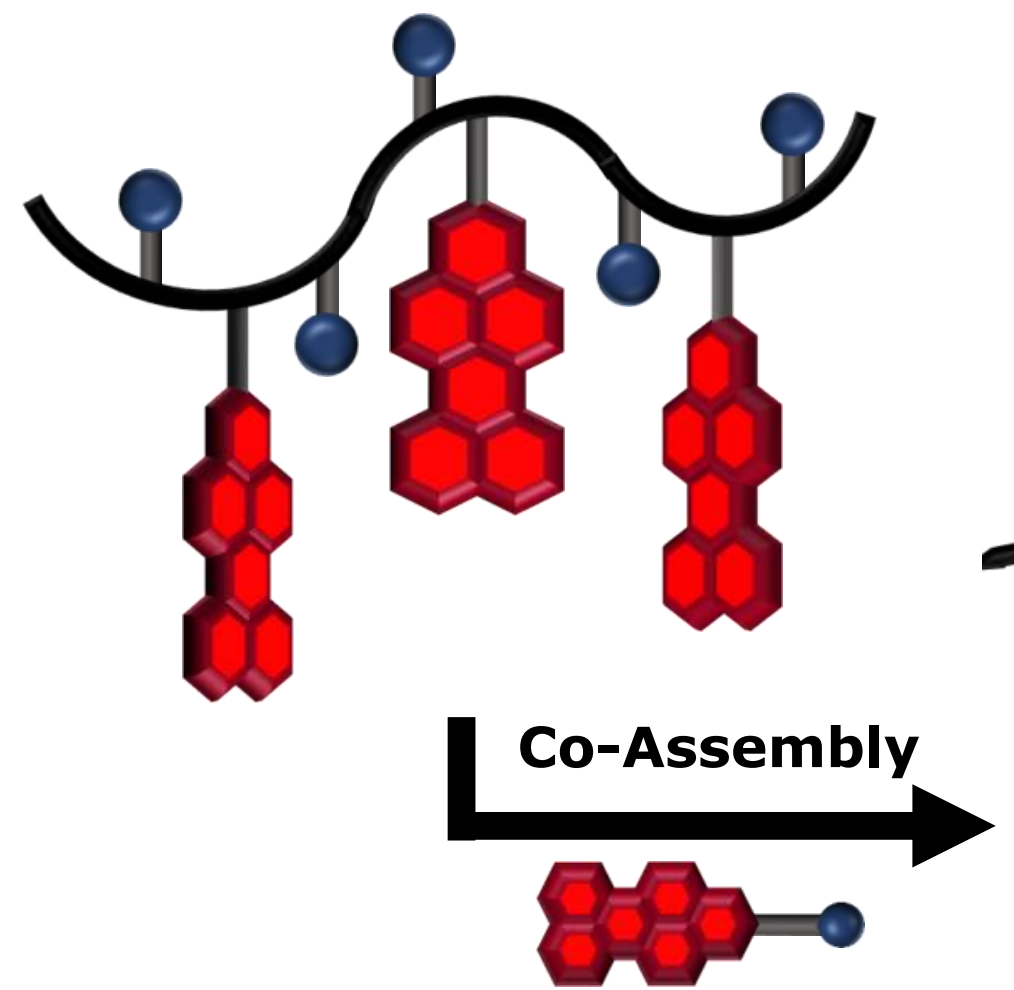

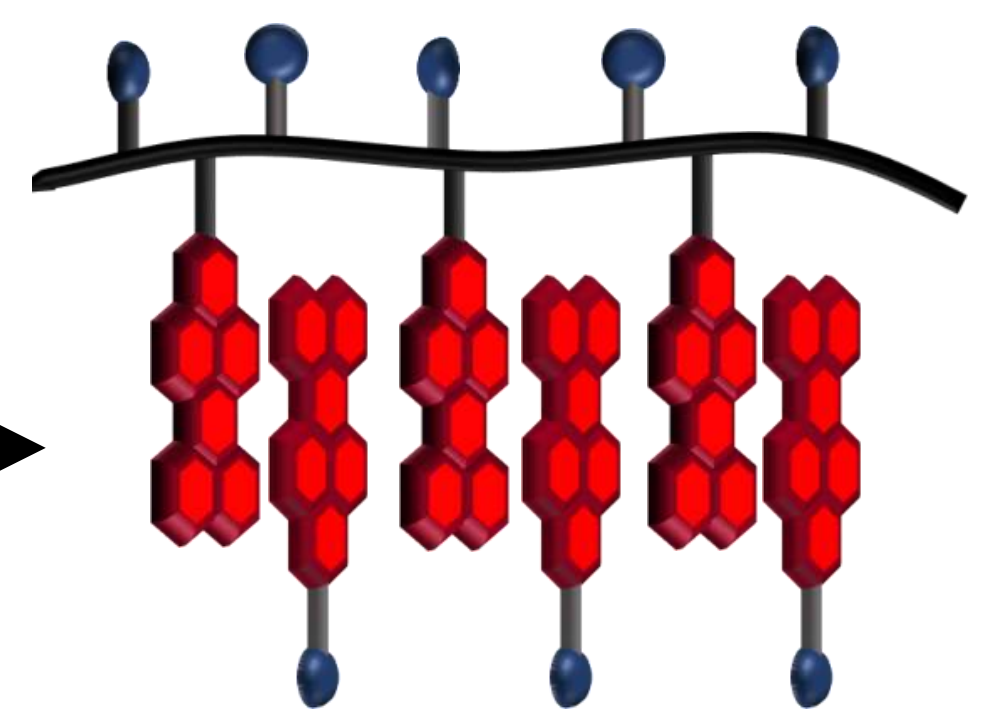

Co-Crystallization

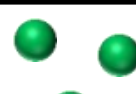

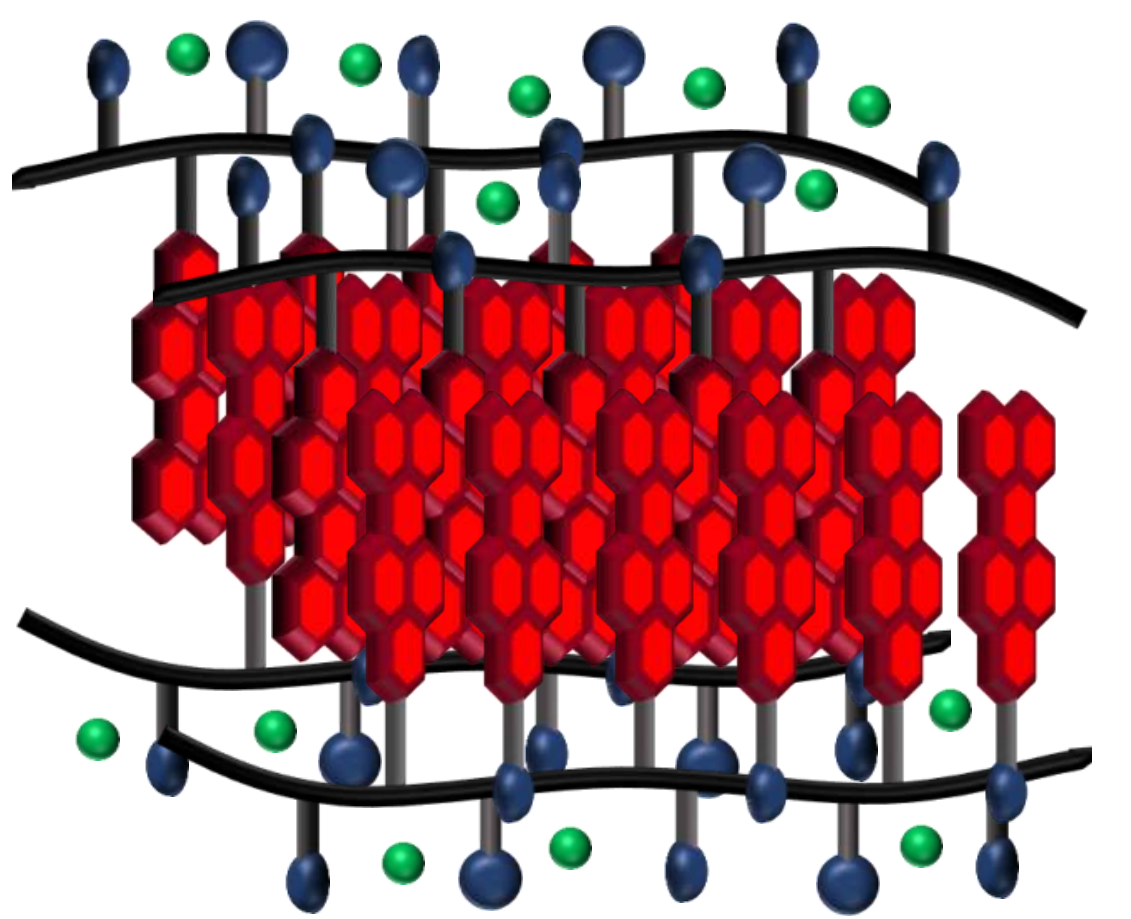

10

With these covalent and supramolecular polymers in hand, the next step is to look at how these two polymer can form a supramolecular alloy. The rationale behind the selfassembly, is that the two molecules can co-assemble and then co-crystallize to form a substitutional alloy. 


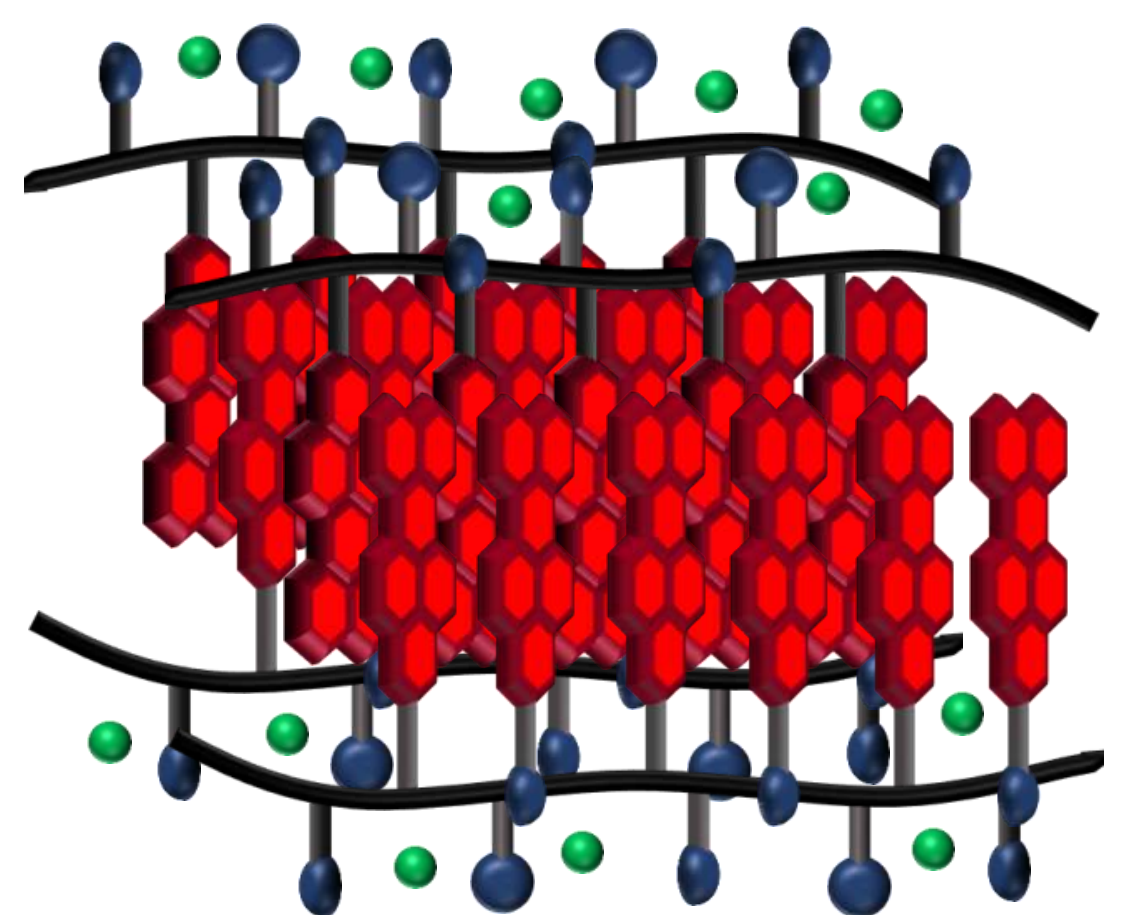

口 "High" lonic Strength

$$
\rightarrow 50 \mathrm{mM} \mathrm{NaCl}
$$

- Constant Charge

$$
\rightarrow \mathrm{pH} \sim 7
$$

$\square$ Long Annealing Times

$\rightarrow 1 \mathrm{~h}$ at $95^{\circ} \mathrm{C}, 18 \mathrm{~h}$ slow cool

\section{Co-Assembly Ratio}

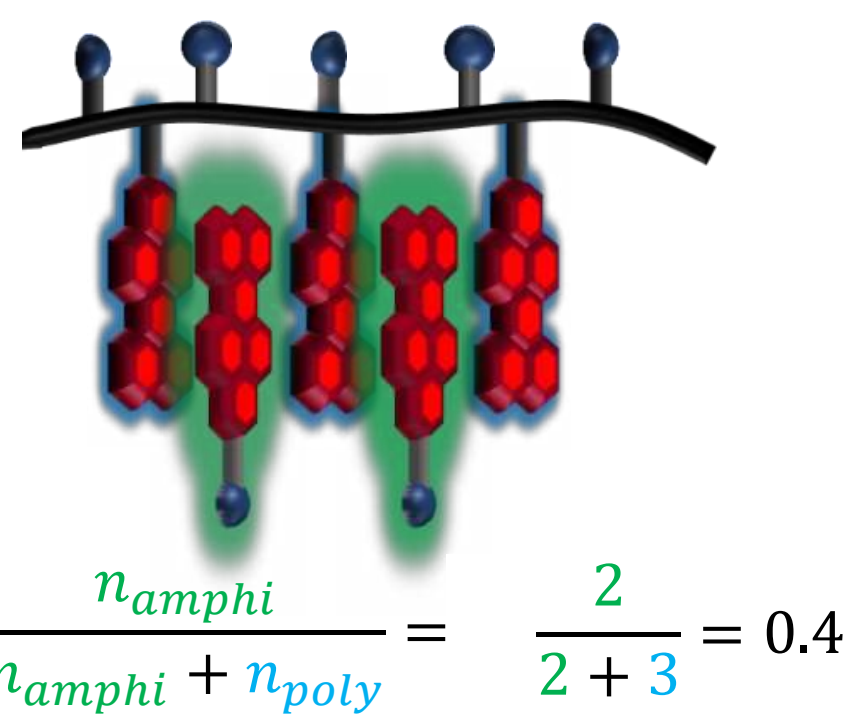

$\phi=0:$ covalent polymer

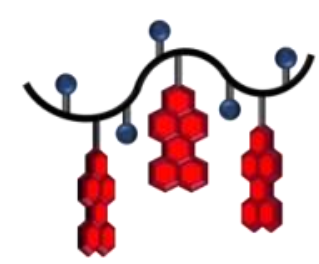

$\phi=1$ : supramolecular polymer

To drive the co-assembly towards equilibrium, the samples were annealed in a dielectrically screened aqueous environment before characterization. In order to more rigorously define the co-assembly of the two structures, we define the co-assembly ratio $(\phi)$ as the number of chromophores on a CA divided by the total number of chromophores in the system, with the limits of $\phi=0$ corresponding to pure covalent polymer and $\phi=1$ corresponding to pure supramolecular polymer. 

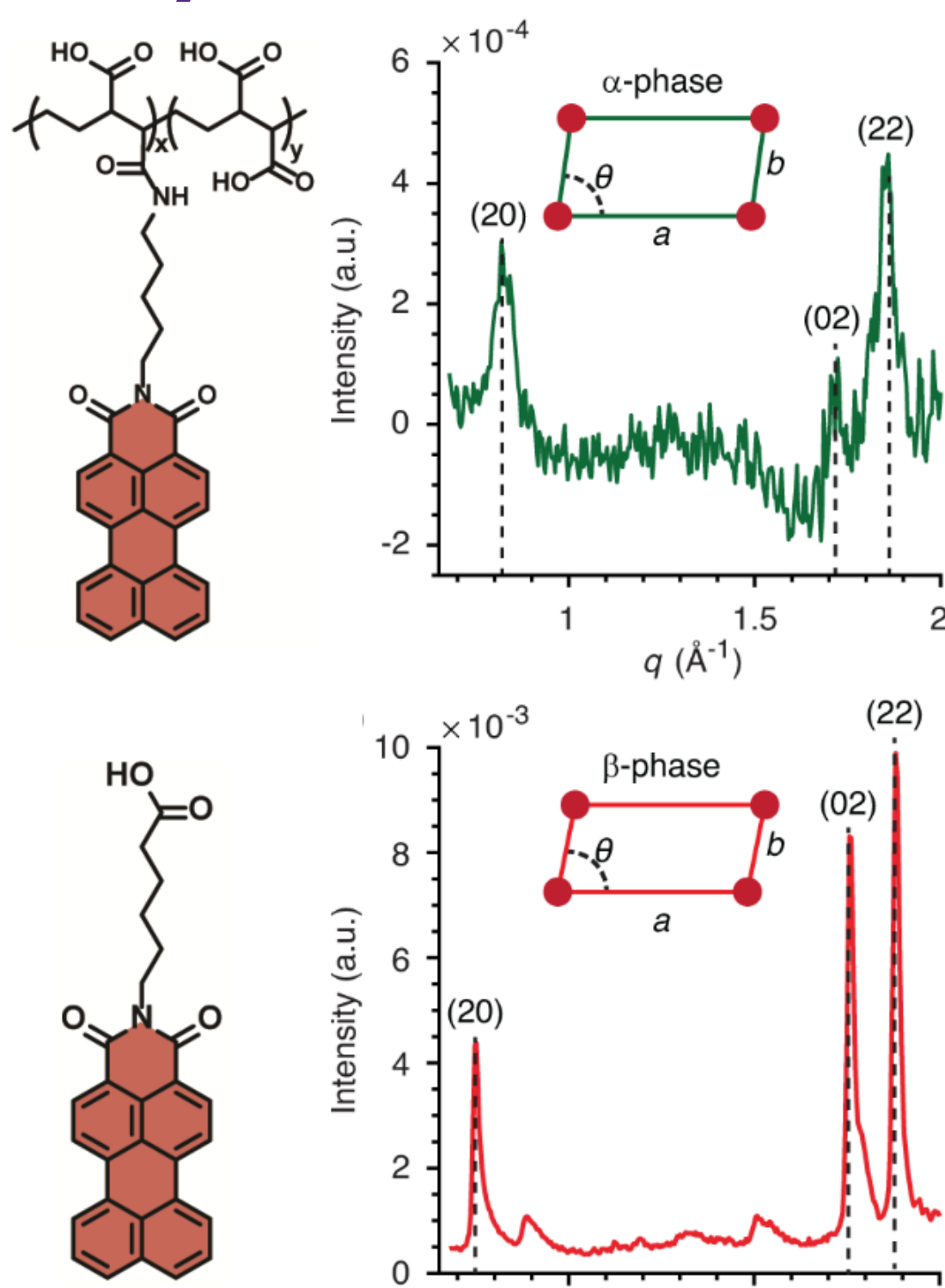

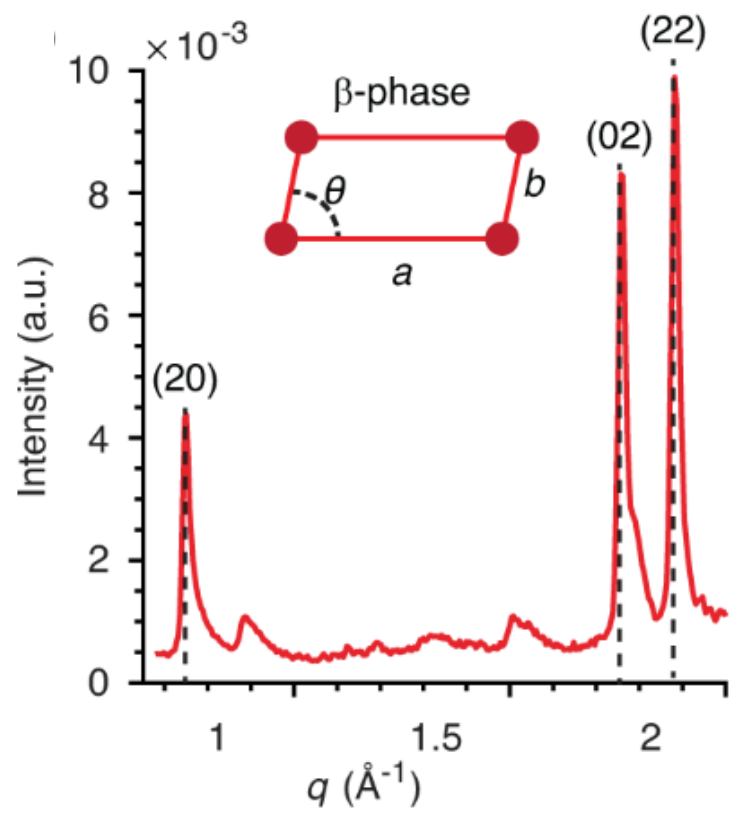

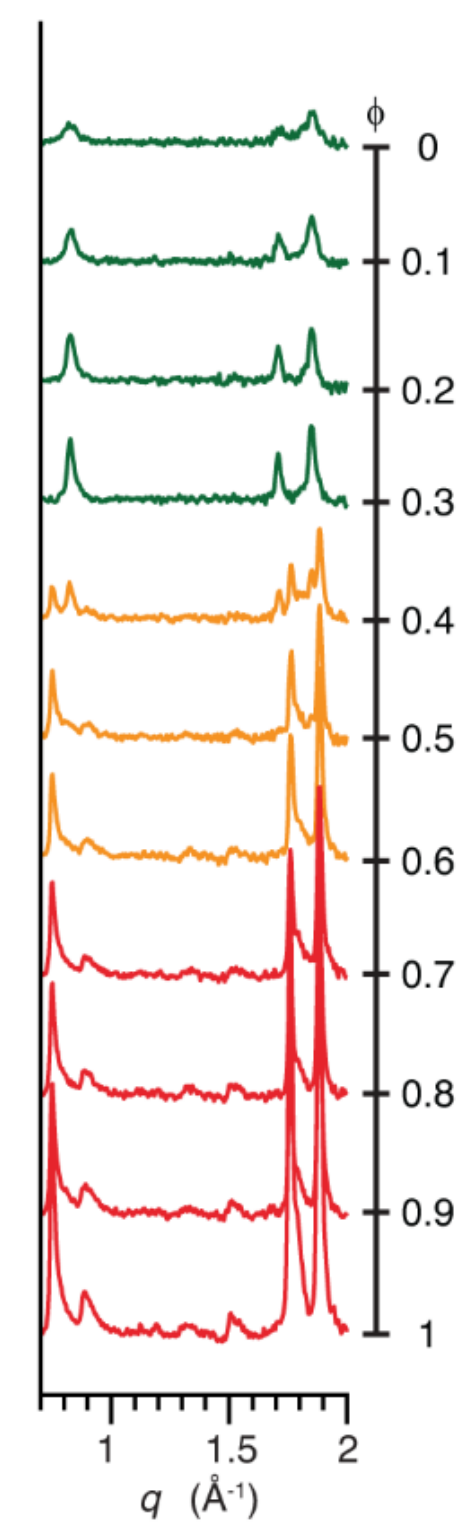
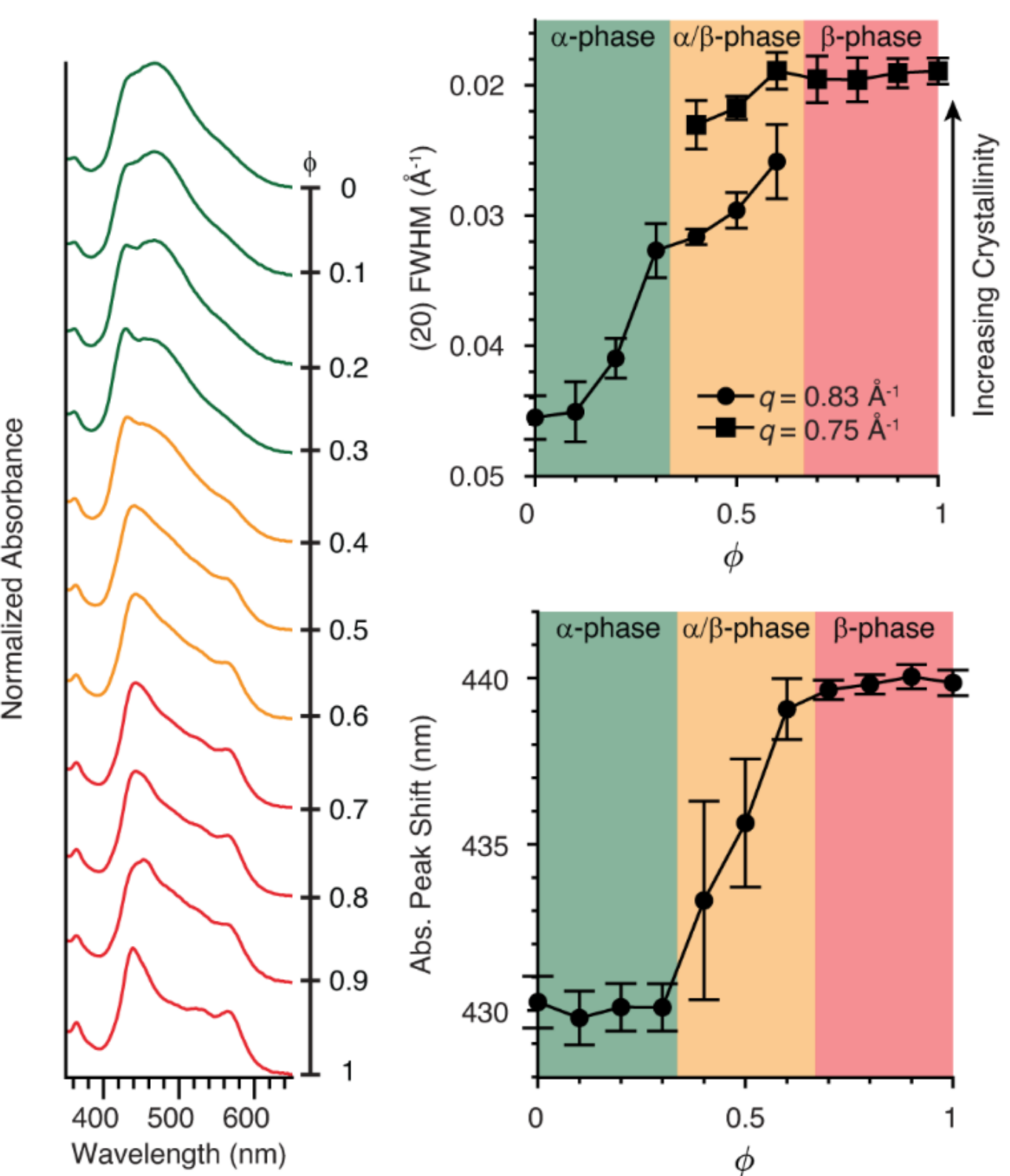

\section{Northwestern ENGINEERING}

As $\phi$ increases from 0 to 1 we observe three distinct phase regimes. From $\phi=0$ to $\phi=0.3$, the scattering peaks from the WAXS of the $\alpha$-crystal phase show an increase in the intensity and decrease in the full width at half maximum (FWHM) indicating an increase in the crystalline domain size. This is indicative of the formation of a substitutional molecular alloy, where the addition of free CA alloys into the $\alpha$-crystal phase formed by the covalent polymer and increases the $\alpha$-phase crystalline domain size rather than forming a separate $\beta$-phase. As the co-assembly ratio increases from $\phi=0.4$ to $\phi=0.6$ we observe a second distinct region in the phase-space where the $\beta$-crystal begins to nucleate and emerge in the scattering pattern while the $\alpha$-crystal phase decreases in intensity. This behavior is indicative of a phase co-existence regime between the $\alpha$ - and $\beta$-crystal phases, which is a behavior commonly seen in more traditional metallic and ceramic alloys. Finally, from $\phi=0.7$ to $\phi=1$ the $\beta$-crystal phase is the only crystal phase detected in the WAXS pattern indicating that the PMI chromophores on the covalent polymer are fully alloying into the $\beta$-crystal phase formed by the CA. 

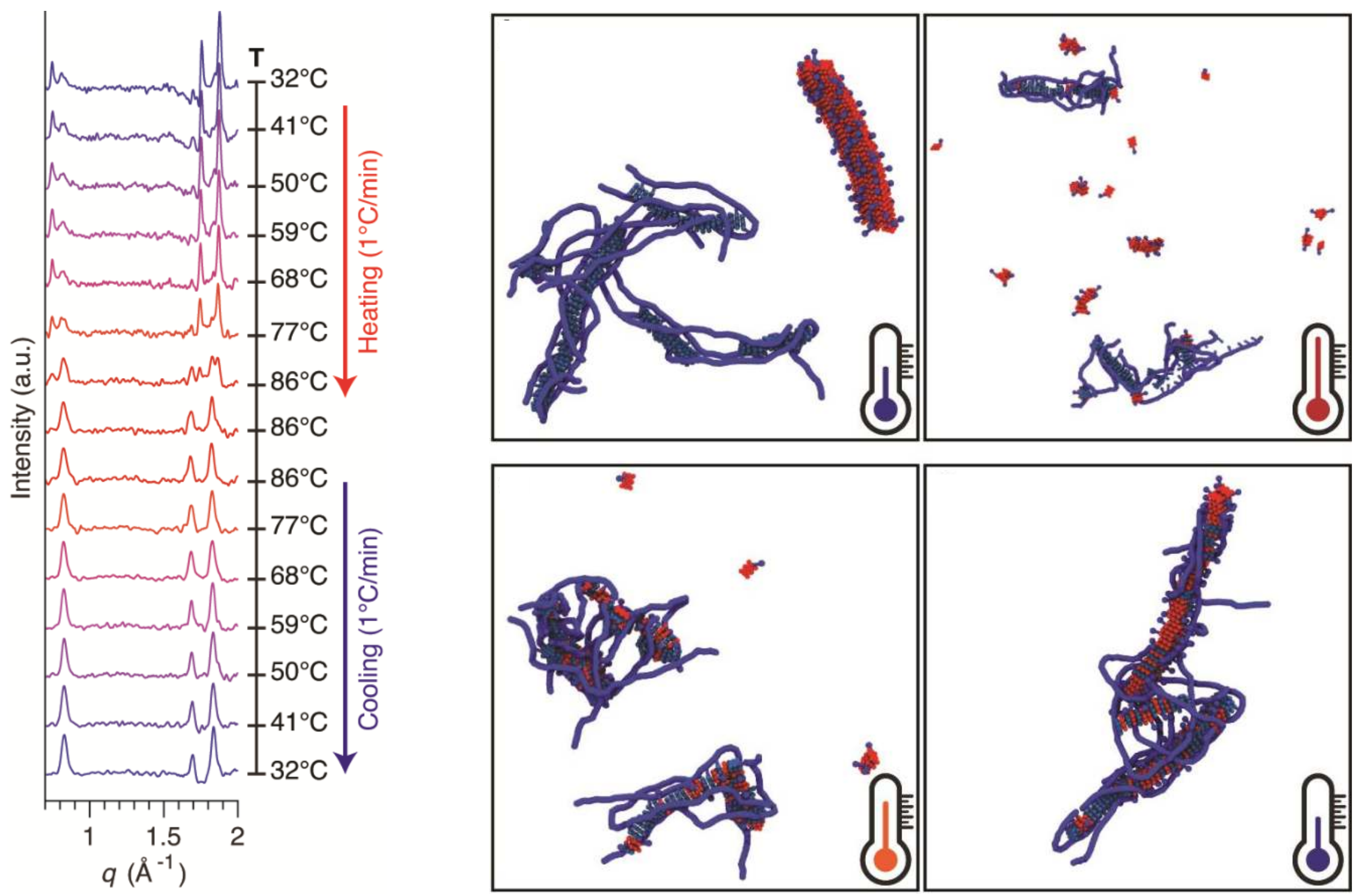

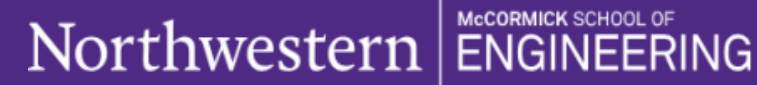

To further understand the co-assembly process, we used variable temperature WAXS to characterize the growth of nanostructures during the annealing process. For the VTWAXS experiments we took pre-annealed nanostructures of CA $(\phi=1)$ and covalent polymer $(\phi=0)$ and mixed them at room temperature. We then annealed these metastable mixtures and used in-situ WAXS to measure the change in crystal structure at different temperatures to characterize the formation of the supramolecular alloy. The VT-WAXS patterns show the initial kinetically trapped state at room temperature contains both the $\alpha$ - and $\beta$-phase crystal. As the structures are heated, the $\beta$-phase crystal begins to melt between $68{ }^{\circ} \mathrm{C}$ and $77^{\circ} \mathrm{C}$ then is incorporated into the $\alpha$-phase crystal as shown by the decrease in the (20) $\beta$-phase peak intensity and the subsequent growth of the (20) $\alpha$ phase peak. CG-MD simulations of the annealing process show the same phenomenon where the $\beta$-phase crystal melts into a mixture of monomeric and aggregated CA, which then incorporate into the $\alpha$-phase of the covalent polymer. 

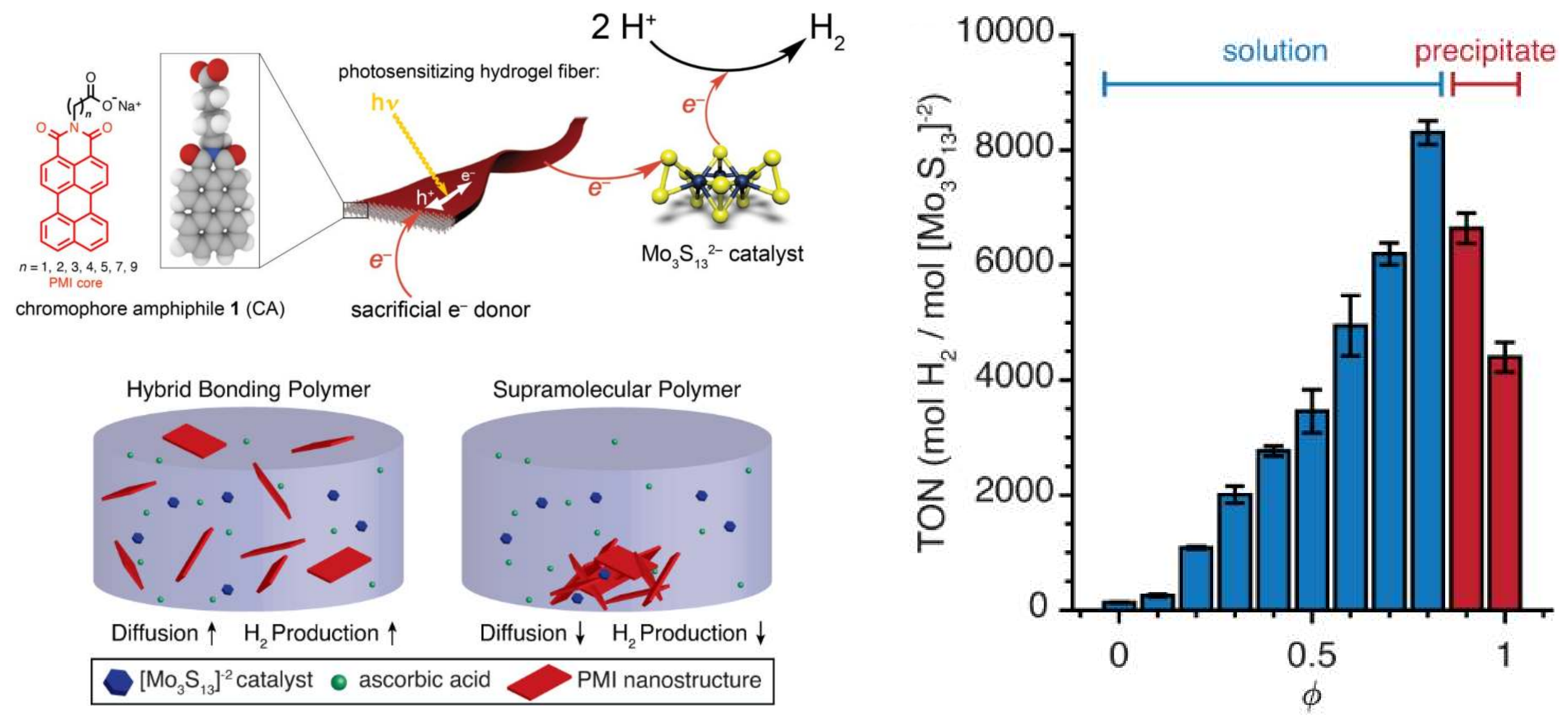

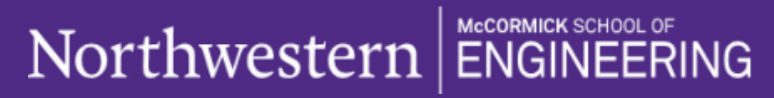

The $\beta$-phase crystal has previously been shown to be excellent photosensitizers for the photocatalytic generation of hydrogen, so we assessed the impact of the alloying composition on the production of hydrogen. Structures at varying values of $\phi$ were irradiated in the presence of a thiomolybdate cluster, acting as the proton reduction catalyst, and ascorbic acid, which acts both as a source of protons and as a sacrificial electron donor, and measuring the turn over number (TON) of hydrogen produced. We found that the highest TON were measured at $\phi=0.8$ which showed a two-fold increase in the TON of hydrogen produced relative to the pure CA. The dramatic difference in TON is likely due to higher diffusion of the catalysts and sacrificial electron donor at the $\phi=0.8$ composition relative to $\phi=1$ composition. The $\beta$-phase at $\phi=0.8$ can remain solubilized in the acidic catalysis environment while the $\beta$-phase at $\phi=1$ forms a dense, precipitate. The resulting increase in diffusion allows for more interactions between the photosensitizer and the thiomolybdate catalyst leading to an increase in hydrogen production. 


\section{Acknowledgements}

\section{The Stupp Group}

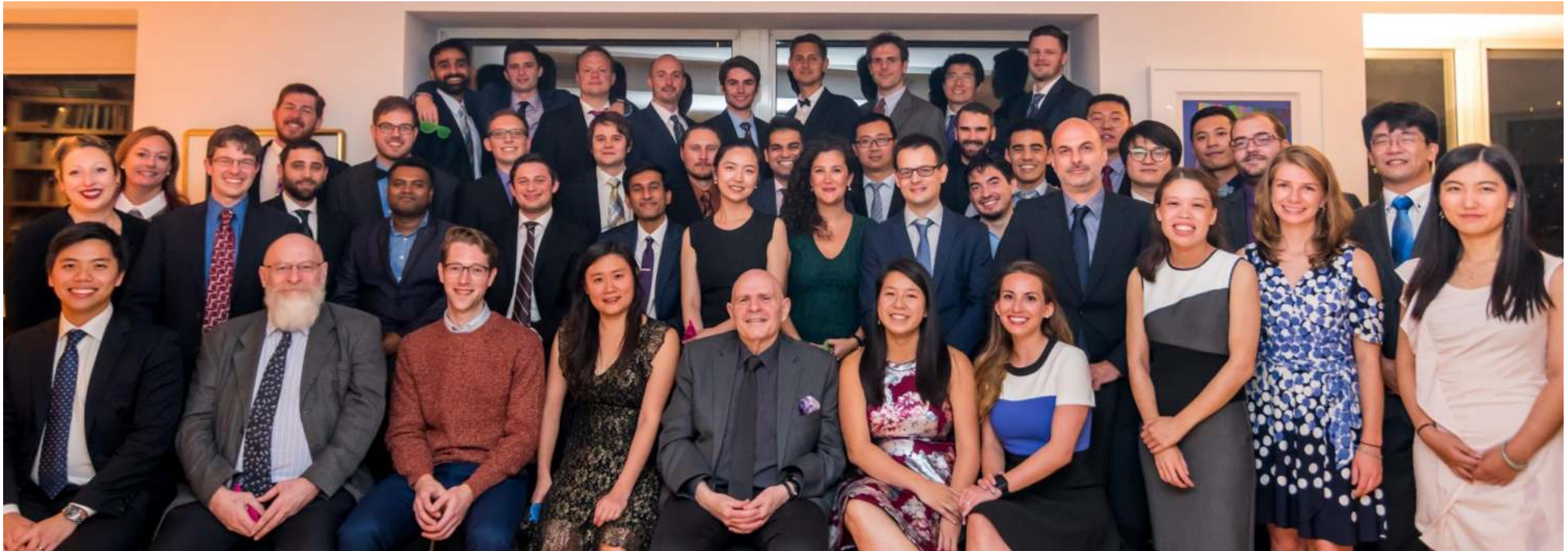

\section{Advisor}

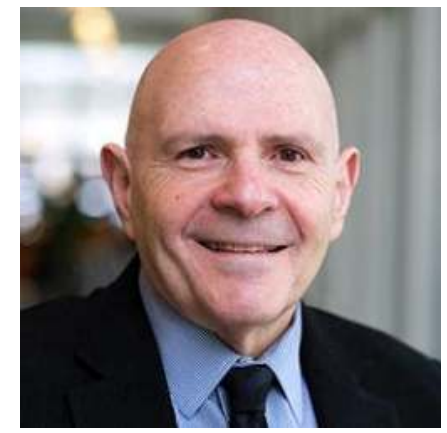

Prof. Samuel Stupp

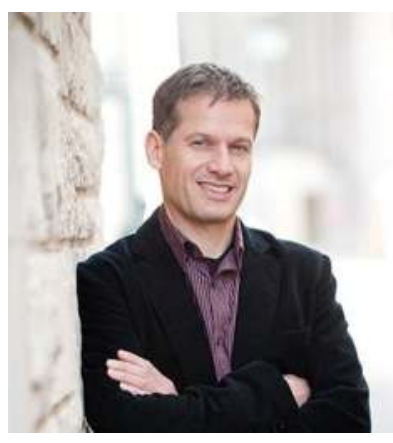

Prof. Erik Luijten

\section{Collaborators}

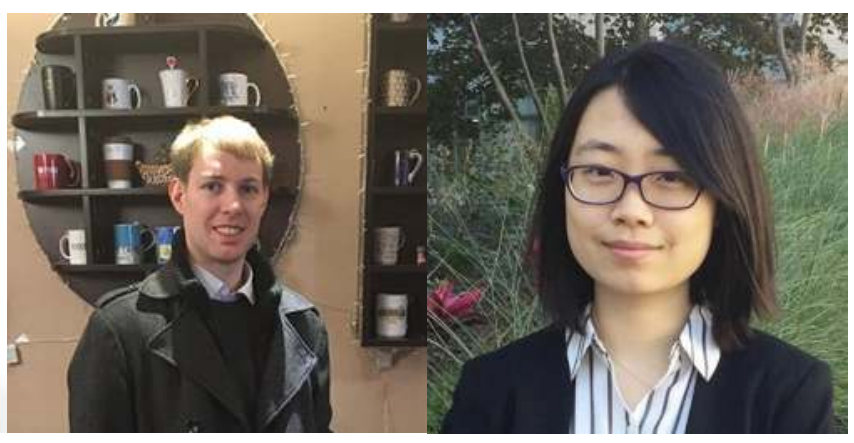

Dr. Tine Curk

Ziwei Wang
Funding Sources

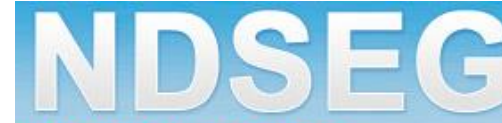

NATIONAL DEFENSE SCIENCE \& ENGINEERING GRADUATE FELLOWSHIP
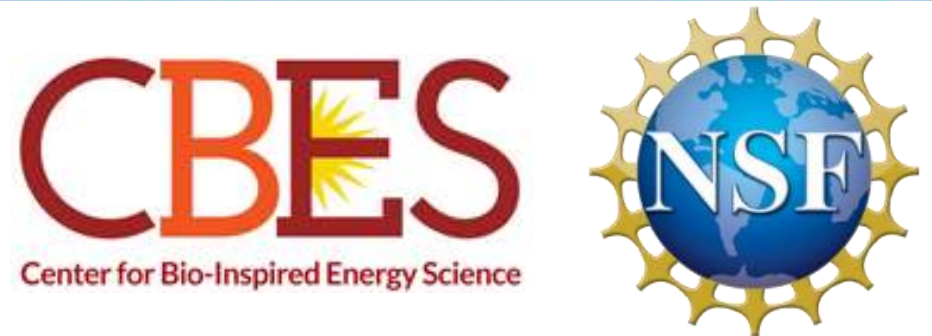

Northwestern | Mecomucrschoolof

Finally, l'd like to thank my advisor Professor Samuel Stupp, my collaborators on this project in the Stupp group, my collaborotors for the coarse-grained simulations in the Luijten group, and my funding sources. 